PNL-SA-22452

THE INFLUENCE OF TRANSMUTATION, VOID SWELLING, AND FLUX/SPECTRA UNCERTAINTIES ON THE ELECTRICAL PROPERTIES OF COPPER AND COPPER ALLOYS

D. J. Edwards

F. A. Garner

L. R. Greenwood

September - October 1993

Presented at the

6th International Conference

on Fusion Reactor Materials

September 27 - October 1, 1993

Stressa, Italy

Work supported by

the U.S. Department of Energy

under Contract DE-AC06-76RLO 1830

Pacific Northwest Laboratory

Richland, Washington 99352 
The Influence of Transmutation, Void Swelling, and Flux/Spectra Uncertainties on the Electrical Properties of Copper and Copper Alloys

\author{
D.J. Edwards, F.A. Garner, and L.R. Greenwood \\ Pacific Northwest Laboratory \\ Richland WA 99352
}

\begin{abstract}
A comparison of the predicted and measured electrical conductivities of MARZ copper and two copper alloys irradiated in FFTF shows that the calculated transmutation rates agree within $15 \%$ with those required to produce the observed changes. It also appears that the contribution of transmutants and void swelling to conductivity changes are directly adcitive. Of the three models studied, Euken's model has been found to best describe the contribution of void swelling to conductivity loss.
\end{abstract}

Pacific Northwest Laboratory is operated for the U.S. Department of Energy by Battelle Memorial Institute under Contract DE-AC06-76RLO 1830. 
Introduction

Copper alloys have been proposed for service as high-heat flux components in fusion reactors $[1,2]$. The electrical and thermal conductivities of these alloys will undergo changes, however, in response to the combined influence of radiation-induced solute redistribution, void swelling, and transmutation [3-7]. Since the transmutation process is very sensitive to neutron spectra, irradiation experiments currently being conducted in the Fast Flux Test Facility (FFTF) will produce levels of transmutants that are atypical of those anticipated from fusion spectra.

For FFTF, some uncertainty still exists in our ability to predict the formation rates of the important transmutants ( $\mathrm{Ni}, \mathrm{Zn}, \mathrm{CO}$ ), with the difficulties arising primarily from uncertainties in the neutron fluxes and spectra actually experienced by the irradiated specimens. Dosimetry measurements usually are not available at the exact location of the specimens within the core.

An estimate of the flux and spectral uncertainties can be made from direct measurement of the transmutants, but in this case the transmutation products are difficult to measure. The three major transmutant isotopes $\left({ }^{64} \mathrm{Ni},{ }^{64} \mathrm{Zn}\right.$, and $\left.{ }^{66} \mathrm{Zn}\right)$ are noi radioactive, thus eliminating the use of any radiation-based techniques such as activation analysis. The ${ }^{60} \mathrm{Co}$ isotope is radioactive, however, and although the levels produced in FFTF do not measurably influence the conductivity, the isotope does reach levels that 
Page 3

discourage the use of wet chemistry techniques to measure the nickel and zinc concentrations.

One other approach to address this problem is to use the observed changes in electrical conductivity to assess the accuracy of the calculated transmutation rates. Even this approach involves some uncertainties, which arise from the lack of full knowledge of the role of various other contributions to conductivity changes. These uncertainties can be addressed, however, by comparing two types of alloys with different responses to irradiation.

This report presents an assessment of the contributions of void swelling and transmutation to radiation-induced conductivity changes in annealed MARZ copper (99.999\% pure) and two commercial copper products, the GlidCop CuAl20 and CuA125 alloys manufactured by SCM Metal Products. The CuA120 and CUA125 were $20 \%$ and $50 \%$ cold worked $(\mathrm{CW})$, respectively. The GlidCop ${ }^{\mathrm{TM}}$ alloys are $\mathrm{Al}_{2} \mathrm{O}_{3}$ dispersion strengthened copper alloys that respond quite differently than MARZ copper to neutron irradiation at high temperature $[6,7]$.

\section{Assumptions Employed}

This assessment assumes that the recently revised [8] transmutation rates calculated for FFTF using the REAC code [9] are essentially correct, but possibly perturbed locally to some minor extent. These calculations predict that after 300 effective full power days of irradiation in FFTF, approximately $0.4 \%$ each of nickel and zinc are formed in copper at the core midplane. 
Page 4

Since the cobalt transmutation rates are approximately three orders of magnitude smaller than those of nickel and zinc, it is further assumed that only these latter two elements contribute significantly to the observed decrease in conductivity.

Radiation-induced changes in the dislocation density in both types of copper alloys are assumed not to cause significant changes in conductivity. This is attributed to the fact that in pure copper a cold work level of $50 \%$ lowers the conductivity only by 3 to 4 \%IACS (International Annealed Copper Standard) [10]. The magnitude of this change is negligible compared to the radiation induced changes in conductivity that were observed in these alloys [3-7]. In addition, the starting dislocation densities in the 20\% CW CuAl20 and 50\% CW CuAl25 were found to decrease when the alloys recrystallized 100\% and $40 \%$, respectively, after irradiation to $50 \mathrm{dpa}$ at $-415^{\circ} \mathrm{C}[4,7]$.

It is further assumed that segregation of nickel and zinc does not alter the overall conductivity, provided that separate phases do not form as a result of segregation. Additionally, it is assumed that the $\mathrm{Al}_{2} \mathrm{O}_{3}$ dispersoids in the CuAl20 aid CUAI25 alloys remain undissolved, though they may be redistributed. This latter assumption is important because aluminum and oxygen in solution each exert a strong influence on electrical conductivity, stronger per atom than that of nickel or zinc.

Ho et al. [11] compiled an extensive tabulation of electrical resistivity data for various binary metal alloys, including $\mathrm{CU}-\mathrm{Al}, \mathrm{CU}-\mathrm{Ni}$, and $\mathrm{Cu}-\mathrm{Zn}$. The tabulation included a range of temperatures and compositions, and the authors critiqued each reference to insure the validity of the data. 
Page 5

According to this compilation, nickel increases the resistivity at 1.22

$\mu \circ h m s \cdot \mathrm{cm} / \mathrm{wt} \% \mathrm{Ni}$, and zinc increases the resistivity of copper at 0.25 $\mu \circ h m s \cdot c m / w t \% ~ Z n$. These values are valid for nickel or zinc concentrations of slowt\%.

There are a number of models that have been used to describe porosityinduced changes in electrical or thermal conductivity. In this paper these models are referred to as the Loeb, Russell, and Euken models [12,13,14], and have been evaluated by Wolfer and Garner [15] for irradiated and voided metals. The Russell and Euken models were derived from Maxwell's relation for conductors and resistors. These two models allow the effective thermal conductivity of a porous solid to be calculated assuming a random distribution of either cubical or spherical cavities, respectively $[13,14]$. Loeb's model attempts to take into account more complex cavity shapes and orientations with respect to the flow path of the heat. Wolfer and Garner [15] chose Euken's model as the model having the best physical foundation. They formulated their equations in terms of the void volume fraction (and not swelling) for the special case of randomly oriented, spherical voids. Figure I offers a comparison between the three models, revealing that a significant difference exists at lower and intermediate void volume fractions.

Due to the difficulty of measuring thermal conductivity on highly radioactive specimens, electrical conductivity is measured in its place. This approach is based on the direct proportionality between the two conductivities at a given temperature, according to the Wiedemann-Franz law: 


$$
\sigma=\frac{x}{L T}
$$

where $L$ is the Lorenz number and $T$ is the absolute temperature. The equations were then formulated in terms of electrical resistivity, $p$, using the inverse relationship $p=1 / \sigma$. The swelling contribution in each model is assumed to operate on the transmutation-enhanced value of resistivity, represented by ( $p_{0}$ $\left.+P_{\text {trans }}\right)$. The nodified equations are listed below:

Modified Loeb's equation $\rho^{\text {eff }}=\left(p_{0}+p_{\text {trans }}\right)\left[\frac{1}{1-\left(\frac{\Delta V}{V_{f}}\right)^{2 / 3}}\right]$

Modified Russell's equation $\rho^{\text {off }}=\left(\rho_{0}+\rho_{\text {trans }}\right)\left[\frac{1+\frac{\Delta V}{V_{f}}-\left(\frac{\Delta V}{V_{t}}\right)^{2 / 3}}{1-\left(\frac{\Delta V}{V_{t}}\right)^{2 / 3}}\right]$

Modified Euken's equation $\rho^{\text {eff }}=\left(\rho_{0}+\rho_{\text {tzans }}\right)\left[\frac{1+\frac{1}{2}\left(\frac{\Delta V}{V_{f}}\right)}{1-\frac{\Delta V}{V_{I}}}\right]$

where $\Delta V / V_{f}$ is the void volume fraction.

The effective electrical resistivity $p^{\text {eff }}$ was calculated using each of the three models. The electrical conductivity was calculated from the effective resistivity by using the following equation: 
Page 7

$$
\sigma=\frac{172.41}{p^{0 . f E}}(8 I A C S)
$$

since a copper wire with 100 \%IACS conductivity has a corresponding resistivity of $1.7241 \mu \mathrm{ohm}-\mathrm{cm}[16]$.

\section{Results}

The swelling measured in CuA120 to date is very small ( $<1 \%$ at $150 \mathrm{dpa}$ ) and somewhat variable from specimen to specimen. No swelling has yet been measured in CuA125. Therefore, these two materials were chosen to assess the validity of the recently revised REAC calculations of transmutation [8]. The predicted increase in resistivity for CuAl20 was found to be overpredicted using REAC-calculated rates. If the transmutation rates were reduced by $15 \%$, however, the predicted and measured values agreed reasonably well (as shown in Figure 2) with the best fit arising from either the Russell or Euken models. These two models yield essentially the same result at low values of swelling. Using the $15 \%$ reduction in predicted transmutation rates, the predicted and measured values for the CuAl25 also agreed reasonably well. This is shown in Figure 3, which also illustrates the combined effect of transmutation and void swelling on the conductivity of MARZ copper. The effect of transmutation remains unchanged, but the measured swelling rate of $-0.5 \% / \mathrm{dpa}$ causes the conductivity of MARZ copper to fall rapidly throughout the irradiation sequence. Again, Euken's and Russell's models yield similar results; however, 
it appears that Euken's model matches the data more closely. As with the previous calculations for the two GlidCop ${ }^{\mathrm{TM}}$ alloys, a $15 \%$ reduction in the predicted transmutation rate was used to provide a better fit.

\section{Discussion}

From the viewpoint of the authors, the two GlidCop ${ }^{T H}$ alloys were best suited for demonstrating the importance of the transmutation elements since both alloys displayed excellent swelling resistance and did not show any evidence of segregation of nickel and zinc. The primary question concerning the GlidCop ${ }^{T M}$ alloys are a) how well does the oxide dispersion resist dissolution under irradiation, and b) do aluminum and oxygen play a role in the conductivity behavior?

Ejwards and coworkers $[7,17]$ recently completed a microscopy analys is of the unirradiated and the irradiated GlidCOP ${ }^{T M}$ alloys that revealed that the $\mathrm{Al}_{2} \mathrm{O}_{3}$ particles were indeed present after irradiation. The analysis showed that, although a small fraction of the aluminum might be in solution, most of the aluminum had either precipitated out of solution to form small spherical oxide particles (4 to $7 \mathrm{~nm}$ in diameter), or remained in the form of large $(>100 \mathrm{~nm}) \alpha-\mathrm{Al}_{2} \mathrm{O}_{3}$ inclusions that were introduced during production of the initial material. Consequently, the assumption that the oxide particles remained effectively undissolved appears to be a valid assumption.

Although the new population of spherical particles in the irradiated material was the result of radiation-enhanced thermal coarsening $[7,17]$, the redistribution of aluminum and oxygen apparently does not affect the post- 
irradiation conductivity. This indicates that the steady state concentration of aluminum and oxygen during irradiaticn is relatively small, and that both elements precipitate out of solution very rapidly after the reactor is shut down. This conclusion is supported by the close agreement between the measured and predicted conductivity, where the possible influence of aluminum and oxygen was not included in the prediction.

Most of the conductivity loss in the MARZ copper arises from the void swelling, with the transmutation in this case a secondary consequence of irradiation. The Euken model also appears to offer a marginally better prediction of the void contribution to changes in the electrical properties at higher swelling levels. Data scatter associated with the difficulty of measuring electrical resistivity on such highly radioactive specimens precludes a more confident comparison between the Russell and Euken models, but Wolfer and Garner [15] thought the Euken model was more physically realistic.

Segregation of the transmutant elements did not appear to have a significant effect on the conductivity of either the MARZ copper or the GlidCOP ${ }^{\text {TM }}$ alloys. Segregation of transmutant nickel to void surfaces in MARZ copper has been observed in a recent study by Muroga and Garner [18]. In a separate and earlier study, Muroga and coworkers [19] found that nickel in Cu$\mathrm{Ni}$ and $\mathrm{Cu}-\mathrm{Ni}-\mathrm{Zn}$ alloys segregated to grain boundaries under electron irradiation. Zinc was found to migrate away from the defect sinks under electron irradiation [19]. No precipitation occurred as a consequence of this redistribution. Despite removing the nickel from solution in the copper 
matrix, the overall effect of the segregation to void surfaces (without precipitation) is thought to be negligible when averaged over the entire specimen. Those regions adjacent to voids that have a high nickel concentration will have a much lower conductivity than those regions in the bulk where the nickel concentration is less, and the conductivity correspondingly higher. Consequently, averaged over the entire specimen, the effect of the nickel segregation is not noticeable.

The work of Edwards and coworkers $[5,7]$ on a mechanically alloyed Cu$\mathrm{HfO}_{2}$ alloy demonstrated that nickel segregation car in some rases increase the electrical conductivity. The post-irradiation examination of this alloy revealed that the electrical conductivity attained a plateau after irradiztion to $50 \mathrm{dpa}$ and higher $[5,7]$. Energy dispersive spectroscopy proved this to result from transmutant nickel segregating to and being incorporated into the large 0.1 to $1 \mu \mathrm{m}$ diameter $\mathrm{HfO}_{2}$ particles. This effectively removes the nickel from the matrix and places it in the unirradiated material in regions that were originally non-conducting.

Overall, the modelling attempted in this study produced reasonable agreement with the predicted transmutation levels, but only after the transmutation rates were reduced by $15 \%$. A $15 \%$ decrease in the transmutation rates does not necessarily require, however, that the displacement rates be decreased by $15 \%$. While most displacements result from neutrons having relatively high energies, the nickel and zinc transmutants are produced. primarily by lower energy neutrons [8]. The flux uncertainties at these lower energies are larger, due not only to calculational and measurement 
difficulties, but also to the presence of neighboring experiments which may contain materials, such as europium oxide, that are strong absorbers of neutrons at lower energies. A problem of this nature was observed in the ${ }^{59} \mathrm{Ni}$ isotopic tailoring experiment also conducted in MOTA [20]. Since the ${ }^{63} \mathrm{Cu}$ and ${ }^{65} \mathrm{Cu}(n, \gamma)$ reactions exhibit a similar dependence on neutron energy, it is felt that reducing both the nickel and zinc transmutation levels by the same percentage is a realistic assumption.

The accuracy of the transmutation calculations also depends on uncertainties in the nuclear cross sections involved. The production of $\mathrm{Ni}$ and $Z n$ depends primarily on the $C u(n, \gamma)$ neutron cross sections and the ratio of $\mathrm{Ni} / \mathrm{Zn}$ mainly depends on the decay ratio to ${ }^{64} \mathrm{Ni}$ and ${ }^{64} \mathrm{Zn}$ of ${ }^{64} \mathrm{Cu}(12.7 \mathrm{hr})$. The accuracy of these nuclear properties is on the order of 5 to 10\%. Other uncertainties in the transmutation calculaticns which have not been taken into account arise from small radial flux gradients (about 5\%) in the MOTA assembly and potential neutron self-shielding effects due to the significant quantity of experimental sample materials.

\section{Conclusions}

The predicted levels of solid transmutants produced in MARZ copner and two copper alloys during irradiation in FFTF may be as much as $15 \%$ too high. This difference probably reflects uncertainties in neutron fluxes and spectra at the lower neutron energies. The major contributions to conductivity changes appear to be void swelling and the formation of solid transmutants. These contributions appear to be directly additive. Redistribution of nickel 
Page 12

and zinc transmutants does not appear to affect the conductivity behavior of pure copper and the GlidCop ${ }^{\text {TM }}$ alloys. 


\section{References}

[1] R.W. Conn, V.A. Chuyanov, N. Inoue, and D.R. Sweetman, Scientific American (April 1992) p. 103.

[2] G. Yieider, A. Cardella, M. Akiba, R. Matera, and R. Watson, Fusion Eng. and Design, 16, (1991) p. 23.

[3] F.A. Garner, H.R. Brager, and K.R. Anderson, J. Nucl. Mater., 179-181 (1991) p. 250.

[4] K.R. Anderson, F.A. Garner, M.L. Hamilton, J.F. Stubbins, Proceedings of the 15th ASTM International Symposium on Effects of Radiation on Materials, June 1990, ASTM STP 1125 (1992) p. 854.

[5] D.J. Edwards, J.W. Newkirk, F.A. Garner, M.L. Hamilton, A. Nadkarny, and P. Samal, J. Nucl. Mater. 191-194 (1992) p. 416.

[6] F.A. Garner, M.L. Hamilton, D.J. Edwards, J.W. Newkirk, J.F. Stubbins, and M.A. Mitchell, J. Nucl. Mater. 191-194 (1992) p. 386.

[7] D.J. Edwards, Ph.D Dissertation, University of Missouri-Rolla, (May 1993).

[8] F.A. Garner, L.R. Greenwood, and F. M. Mann, Fusion Reactor Materials Semiannuat Report, DOE/ER-0313/13, (Sept. 30 1992) p. 42.

[9] F.M. Mann, Transmutation of Alloys in MFE Facilities as Calculated by REAC, HEDL-TME 81-37, Hanford Engineering Development Laboratory, (August, 1992).

[10] D.E. Tyler, Metals Handbook, 2 10th ed. (ASM International 1990) p. 276. 
Page 14

[11] C.Y. Ho, M.W. Ackerman, K.Y. Wu, T.N. Havill, R.H. Bogaard, R.A. Matula, S.G. Oh, and H.M. James, J. Phys. Chem. Ref. Data, 12 No. 2 (1983) P. 183.

[12] A.L. Loeb, J. Amer. Cer. Soc., 18 (1954) p. 96.

[13] J. Russe11, Amer. Cer. Soc., 18 (1935) p. 1.

[14] A: Euken, Forsch. Geb. Ingenieurw., B3, Forschungsheft No. 353, 1932.

[15] W.G. Wolfer, and F.A. Garner, Damge Analys is and Fundamental Studies Quarterly Progress Report, DOE/ER-0046/17, (May 1984) p. 58.

[16] F. Gregory, A.J. Bangay, and T.L. Bird, Metallurgia, 71 (1965) p. 207.

[17] D.J. Edwards, F.A. Garner, J.W. Newkirk, and A. Nadkarni, this conference.

[18] T. Muroga and F.A. Garner, Fusion Reactor Materials Semiannual Progress Report, DOE/ER-0313/15, 1993, in press, Also accepted for publication in J. Nucl. Mater.

[19] T. Muroga, E. Ishimaru, and N. Yoshida, presented at the 16th International Symposium of Effects of Radiation on Materials, Denver, Co., 1992.

[20] F.A. Garner, M.L Hamilton, L.R. Greenwood, J.F. Stubbins, and B.M. 0liver, presented at the 16th International Symposium of Effects of Radiation on Materials, Denver, Co., 1992. 
Page 15

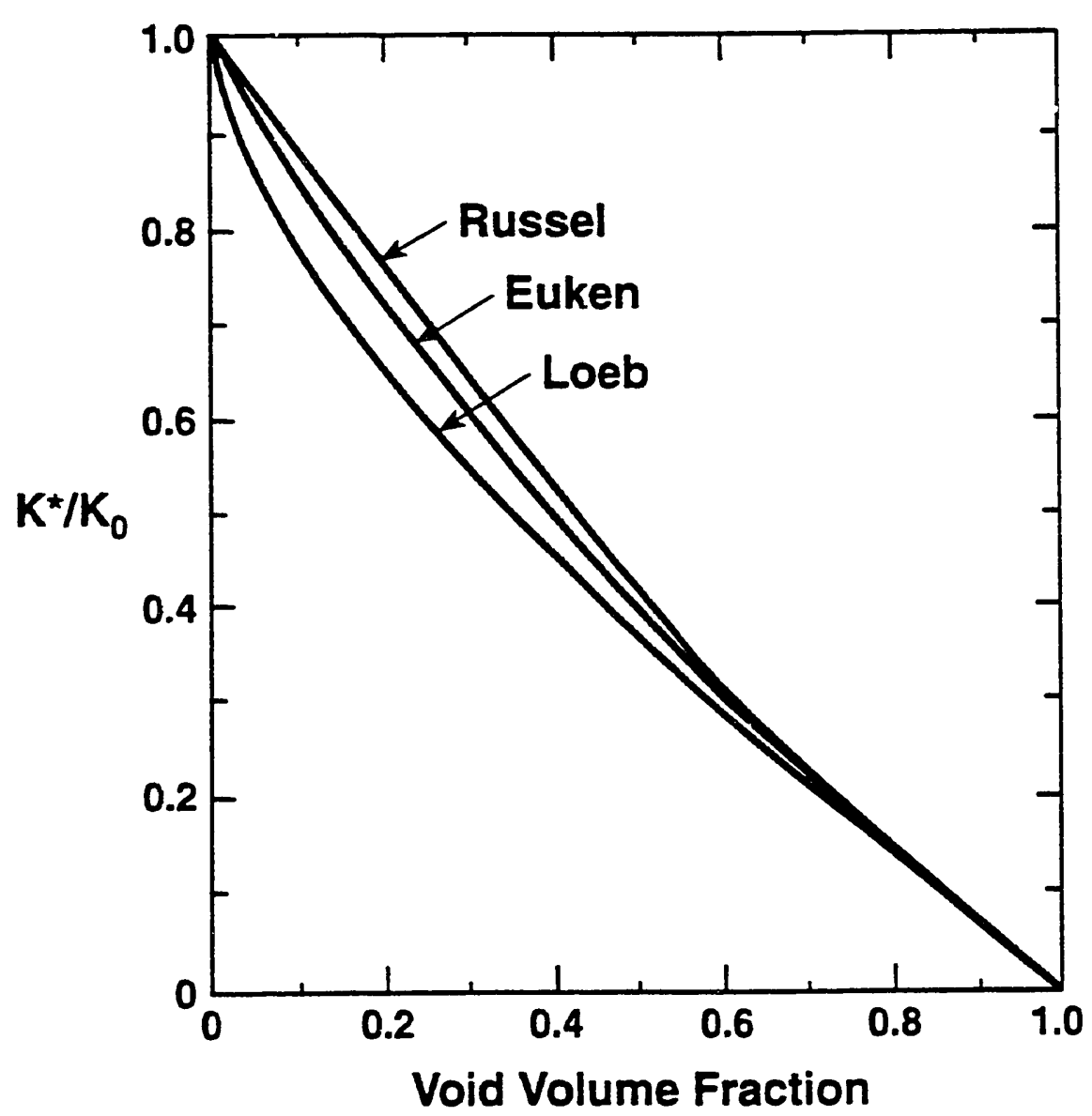

Figure 1 Comparison of various models describing the contribution of voids to thermal conductivity change, as presented by Wolfer and Garner [ref. 15] 


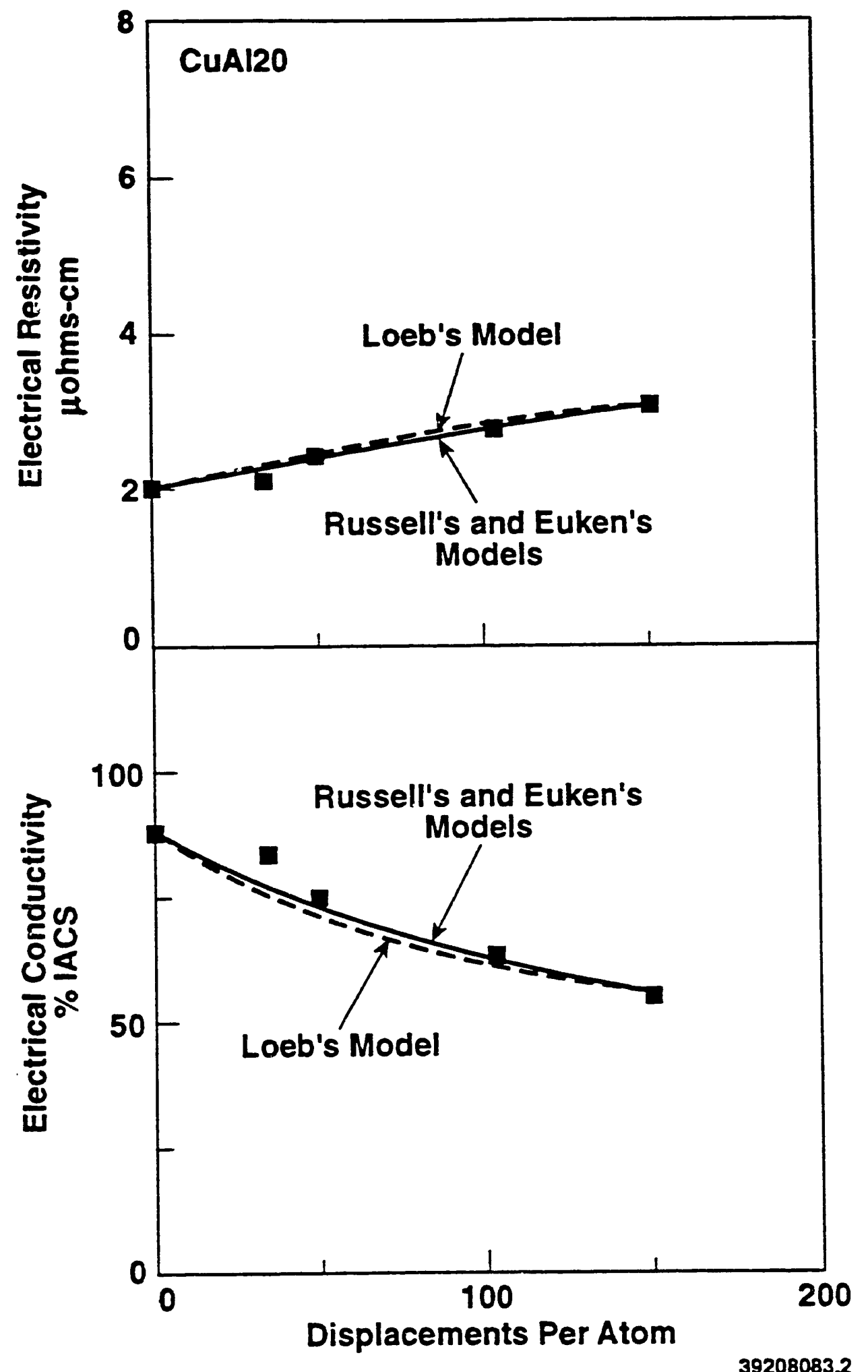

Page 16

Figure 2 Comparison of predicted and observed changes in the electrical behavior of CuAl20, assuming that the transmutation rates are 15\% lower than calculated by the REAC code. 


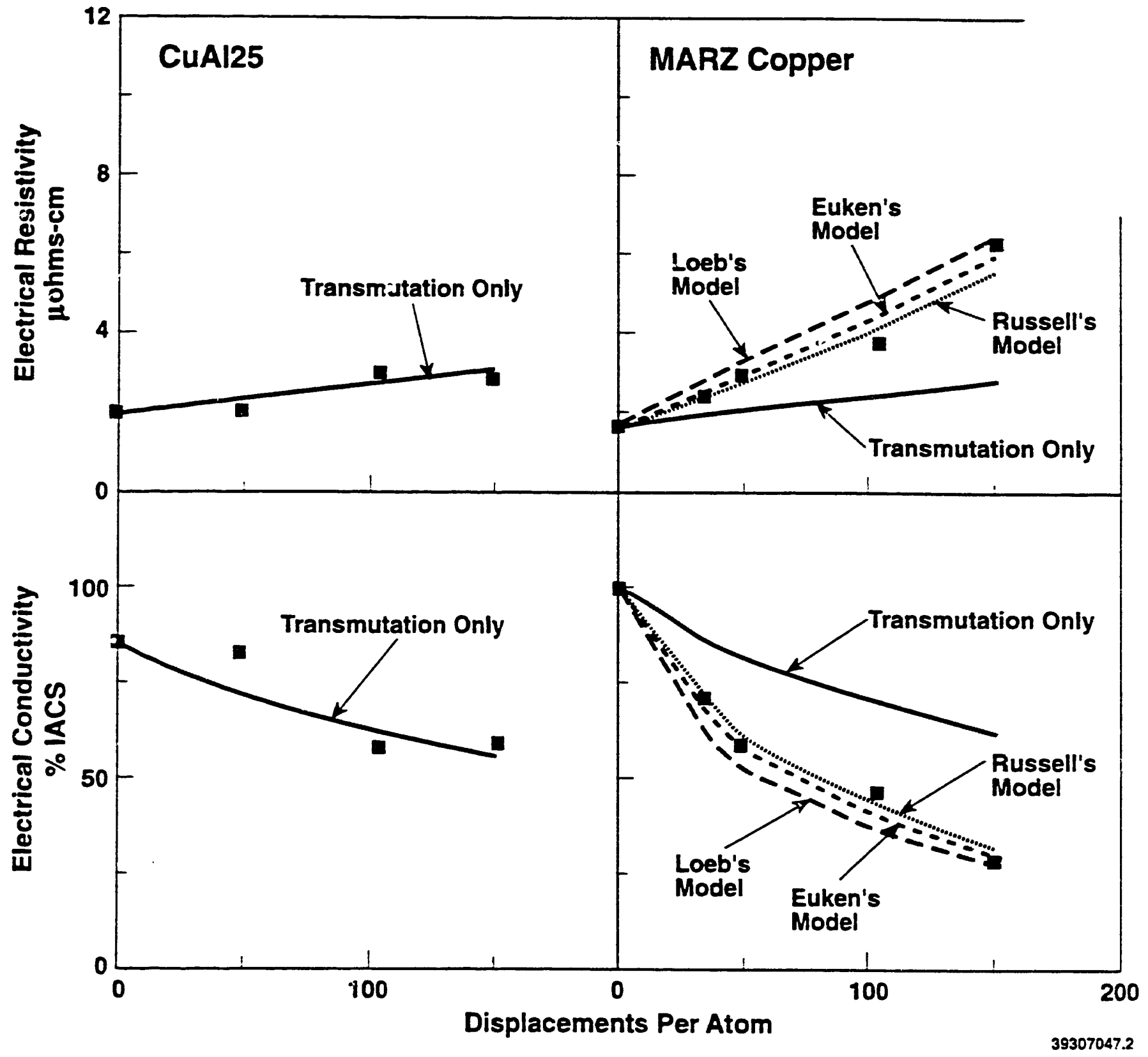

Figure 3 Comparison of predicted and observed changes in the electrical behavior of CuA125 and MARZ copper, assuming that the transmutation rates are 15\% lower than calculated by the REAC code. 


\section{List of Figures}

Figure 1 Comparison of various models describing the contribution of vojds to thermal conductivity change, as presented by Wolfer and Garner [ref. 15]

Figure 2 Comparison of predicted and observed changes in the electrical behavior of CuA120, assuming that the transmutation rates are $15 \%$ lower than calculated by the REAC code.

Figure 3 Comparison of predicted and observed changes in the electrical behavior of CUAT25 and MARZ copper, assuming that the transmutation rates are 15\% lower than calculated by the REAC code. 

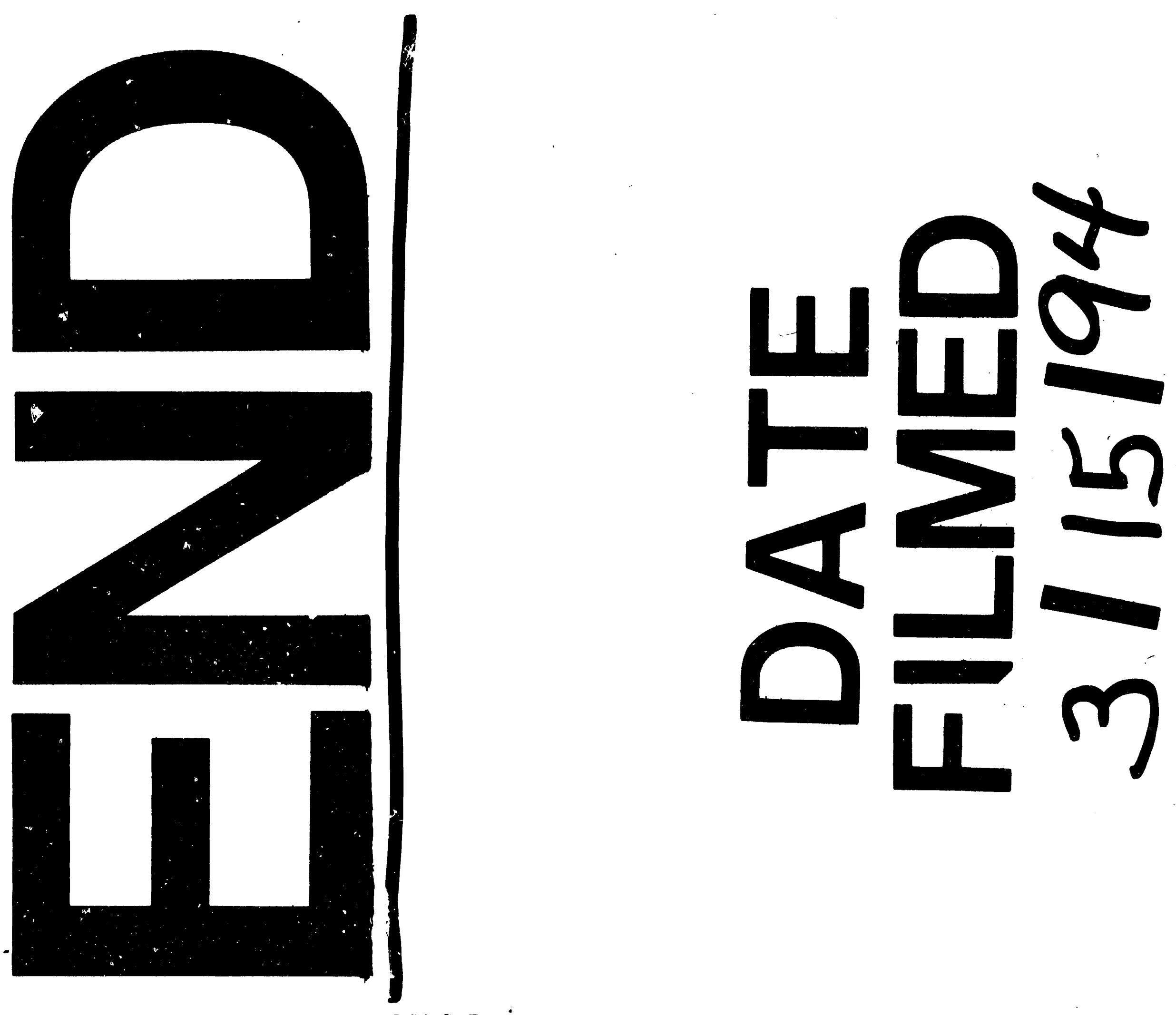